\title{
Environmental Performance of Furniture Layouts in SI Housing
}

\author{
Yong Kyu Yi*1 and Yun Kyu Yi ${ }^{2}$ \\ ${ }^{1}$ Full-time Lecturer, College of Engineering, JEJU National University, Korea \\ ${ }^{2}$ Assistant Professor, School of Design, University of Pennsylvania, USA
}

\begin{abstract}
It is generally acknowledged that non-closed space can be more easily adapted to family lifestyle changes in terms of house planning today, but some residents have raised the issue of indoor environment in the nonclosed space. The aim of this paper is to understand how environmental factors can be changed according to different furniture layouts and to examine how residents respond to the environment condition in different non-closed spaces.

The study utilized computational building simulations to understand the environmental condition and observes the residents' behavior to understand the living style of different furniture layouts. From the simulation results and observation of behavior, the paper compares the environmental condition and the living style to interpret the cause and effect between the environment and behavior.

SI housing (Skeleton and Infill Housing) can be assumed as one of the eligible examples of non-closed space and the study selects an existing SI housing unit to conduct the test. It was found that the environment condition is one of the important factors that influence behavior, and a layout with various environment conditions allows the resident to behave with more ease within their preferred environment condition.
\end{abstract}

Keywords: SI housing; non-closed space; computational fluid dynamics; environmental performance

\section{Introduction}

The decrease of the birth rate and increase of the population over age 65 in East Asia has changed the family structure of today (UN-HAVIT, 2006). KOSIS (Korean Statistical Information Service) reports that the average number of persons per household in Korea is expected to decrease from 3.6 people in 2005 to less than 2.6 people in 2025 (KOSIS, 2009). Hirohara (2002) pointed out that with changes in family structures, the possibility for an occupant to rearrange the residential space is important. Shinohara (2003) and Kazuhiko (2000) stated that changes of family structure have brought about concerns of privacy among family members, and pointed out that the flexibility and adaptation of furniture might offer a possible living solution in the future. Habraken (1998) argued that living is not primarily based on a private room with a function but on territory, and for that reason residential architecture needs to return to using an open living space. Shinohara (2003) also indicated that the house

\footnotetext{
*Contact Author: Yong Kyu Yi, Ph.D., D116 College of Engineering $4^{\text {th }}$ Bldg., JEJU National University,

66 Jejudaehakno, Jeju-si, Jeju, 690-750, Korea

Tel:+82-64-754-3730

E-mail: ykyi@jejunu.ac.kr

(Received October 8, 2009 ; accepted May 11, 2010)
}

should not always be a private room for an individual in a small area separated from others, but a house needs to be a simple, variable device, which creates territory in the small area. It is generally acknowledged that non-closed space can be more easily adapted to the changing family lifestyle. SI housing (Skeleton and Infill Housing) can be assumed as one of the eligible examples for using the non-closed space. SI housing can also be called "Flexible Housing" and "Adaptable Housing," which conceptualize the same idea. In many SI housing projects, creating flexible space can be achieved by moveable storage furniture. Unlike walls, this moveable storage furniture as a partition can create a territory instead of a room. Examples of this can be seen in Archigram's (1967) work "A house for the year 1990" and Yashiro's (2004) study for developing a floor system and box system.

In the author's previous paper (2006) it was reported that some residents raised the issue of the indoor environment in the non-closed space. Even though residents in SI housing can modify furniture layout to adjust their changes in lifestyle, they express dissatisfaction with the thermal and visual conditions. This suggests that building environments can be an important factor to consider in designing the nonclosed space. Indoor environment conditions such as air movement, thermal and visual comfort can be adjusted by changes in the infill (furniture) layout. 
The purpose of this paper is to understand how environmental factors can change according to different furniture layouts and to examine how residents respond to the environment condition in different non-closed spaces. The results can be reported to prospective nonclosed space residents to gain insight and knowledge of the relation between furniture layout and building environment.

The study conducts computational building simulations to understand the environmental condition and observes the residents' behaviors to understand the living style in different furniture layouts. From the simulation results and observation of behavior, the paper compares the environmental condition and the living style to interpret the cause and effect between the environment and behavior. An existing SI housing unit was selected for the test. Three furniture layouts were designed based on the different furniture connection types and the living style conditions. The Computational Fluid Dynamics (CFD) simulation program was utilized for understanding air movement and thermal condition, and a daylight simulation program was used for understanding visual comfort. A research sheet and pictures were utilized for observing the residents' behavior.

\section{Furniture Layouts}

The study selects one unit in an existing apartment building, which was recently renovated as SI housing. It is located in a central area of Tokyo, Japan. The selected house unit has a $57.76 \mathrm{~m}^{2}$ floor area with a ceiling height of $3.05 \mathrm{~m}$. The renovated unit utilizes movable storage furniture to create a residential space. The service area was located in the north part where previously there was a hallway, and the south area, which previously accommodated four individual rooms as a dormitory, was combined to become one open space (Fig.1.).

\subsection{Defining furniture layout types}

The furniture used for this study is slim and has

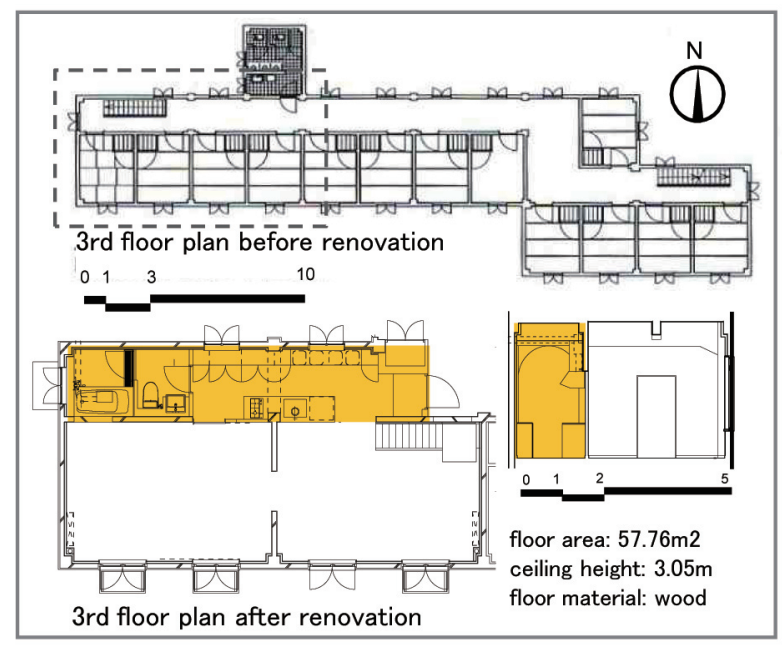

Fig.1. Renovation of Test SI Housing installed casters for mobility. The author's previous study (2008) found that the furniture used in the study is the slimmest furniture among those presently manufactured by four major infill manufacturers in Japan. The furniture with casters is called $\mathrm{T}$ series and without casters is called B series. For size identification, the T series that has a depth of $300 \mathrm{~mm}$ is called type $\mathrm{T} 1$ and the $600 \mathrm{~mm}$ design is called type T2. B series furniture that has a width of $860 \mathrm{~mm}$ is called type B1, and the $300 \mathrm{~mm}$ model is called type B2. Types T1 and T2 have the same width of $860 \mathrm{~mm}$ and height of $2500 \mathrm{~mm}$, and Types B1 and B2 have the same depth of $300 \mathrm{~mm}$ and height of $2500 \mathrm{~mm}$ (Fig.2.).

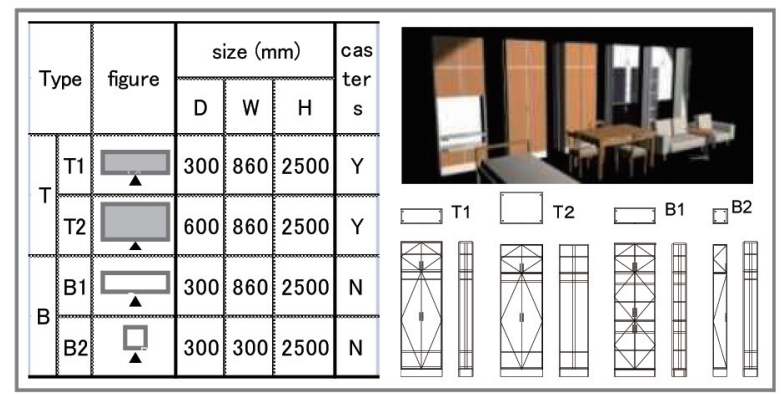

Fig.2. Outlines of Movable Storage Furniture

The paper defines possible furniture layout types that create territory as follows: 1) the length of connected furniture and 2) the relationship between the furniture and skeleton (wall). In this paper, the connection of pieces in a horizontal way is called an I-shape and in a vertical way is called an L-shape, and these can be defined as the basic furniture connecting shapes (the basic shapes). This basic shape can be connected with a number of furniture pieces. In this paper, groups of less than three connected furniture pieces are classified as a "basic type" while groups of three or more are classified as an "expansion type."

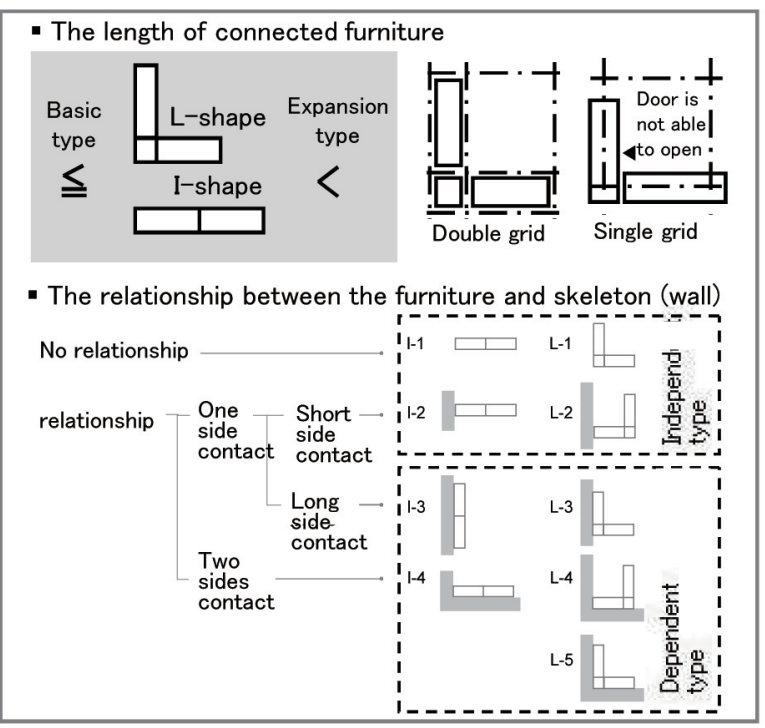

Fig.3. Movable Storage Furniture Layout Types 
Regarding the relationship between the furniture and skeleton (wall), four types of relationship were defined, depending on whether or not furniture was in contact with the skeleton (wall), whether the numbers of the face contact with the skeleton (wall) is one or two, and whether the face contact is long or short. The paper classifies the pattern in which there is either no relationship or only the short side is in contact with the skeleton into "an independent type" and classifies others into "a dependent type" (Fig.3.).

\section{Developing the Layouts for the Test Unit}

To develop the furniture layouts for different living style conditions, the study defined the possible scenarios of living style that can be applied to the test unit. The owner of this unit is a family with two parents who are in their fifties and two daughters who are in their twenties. The family intends to utilize this unit as a second home. The husband expects to use the unit as a temporary office for himself and an acquaintance as a Small Office Home Office (SOHO), or a House with a guest room. The daughters expect to use the unit as a temporary university facility such as a laboratory or a shared house.

All the members of the family expect to use the unit as a cottage in town or a party space. Among these different living style scenarios, the paper focused on scenarios of a SOHO, a laboratory, and a cottage in town.

Four meetings were conducted for the study in February 2006 to design the furniture layout. At the first and the second meetings, a plan drawing was used. At the third and the fourth meetings, a 3D computer model was used to decide the furniture layouts.

The first layout (Layout A) was developed as a SOHO; all four furniture types were selected. To separate private and public space, sofas were located on the east side for a meeting space.

For the second layout (Layout B) type, developed as a laboratory, selected furniture was defined as an expansion and a dependent type. To provide a large public space, everything except the bed area on the west side was incorporated.

The third layout (Layout C) was developed as a cottage in town, and basic and independent furniture were selected. To create two independent sleeping areas, furniture pieces were located between two beds to separate the sleeping area (Table 1).

\section{Environment Conditions for the Different Layouts}

Air temperature, wind speed, and daylight are considered as measurements for the indoor environment condition. In the previous study, these criteria were one of the major concerns revealed by the occupants.

Also, thermal and visual comfort are the key factors to consider in improving the indoor environment.
Table 1. Three Layouts

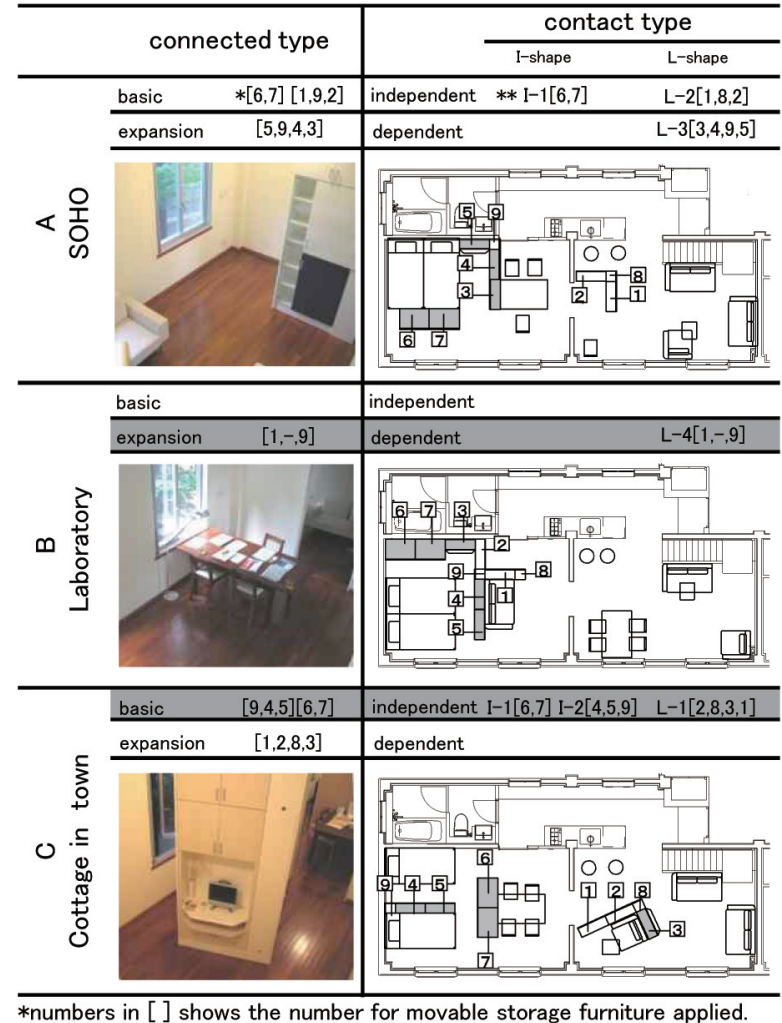

*numbers in [ ] shows the number for movable storage furniture applied. ** T1: 3,4,5 । T2: 6,7 IB1:1,2 B2:8,9

To investigate air temperature and wind speed, this study employs Computational Fluid Dynamic (CFD) simulation programs, and for the daylight, the daylight factor was considered as a measurement.

A CFD model was built to account for both steady state and turbulence. The renormalization group (RNG) based k- $\mathrm{\varepsilon}$ turbulence model with full buoyancy option was used.

For the boundary condition, the predominant flow direction and the natural convection pressure were not specified for the outflows. The pressure field was corrected by solving the Poisson equation developed from the continuity equation and linearized momentum equation. The equations for turbulence, energy, and radiation were solved sequentially thereafter, using the previously updated values of other variables, until convergence was reached. The radiation model was added to the equation models and the mesh used was the rectangular Cartesian grid with a size between $0.087 \sim 0.38 \mathrm{~m}$ and a total number of meshes of 393588 cells.

The daylight factor is used to measure the indoor daylight quality. It describes the ratio of outside illumination over inside illumination and is expressed in a percentage format. The higher the daylight factor, the more natural light is available in the room. Daylight factor is relative to the amount of light entering a space. Thus, even though the condition of the sky changes, the percentage will remain the same. It therefore provides an objective measure for the comparison of alternative design options. 
The selected unit size was 10,920x 5,460mm and the unit has three windows in the front façade and two windows in the rear side with a size of $1,750 \times 1,260 \mathrm{~mm}$ (width $\mathrm{x}$ height) at a height of $700 \mathrm{~mm}$ from the floor. Two Air Conditioning units were installed at each front side corner at a height of 2,300mm (Fig.4.).

\subsection{Air temperature and wind speed}

For air temperature and wind speed, two scenarios of natural ventilation and mechanical ventilation are investigated. For both natural and mechanical ventilation, exterior walls were populated with typical cast concrete (conductivity: $0.38 \mathrm{~W} /(\mathrm{mK})$, density: $1200 \mathrm{~kg} / \mathrm{m}^{3}$, and specific heat $1000 \mathrm{~J} /(\mathrm{kg}$ $\mathrm{K})$ ) and windows were populated with typical glass (conductivity: $1.05 \mathrm{~W} /(\mathrm{mK})$, density: $2300 \mathrm{~kg} / \mathrm{m}^{3}$, specific heat $836 \mathrm{~J} /(\mathrm{kg} \mathrm{K})$, solar transmittance 0.6 , and solar reflectance 0.1$)$ thermal properties. The initial ambient temperature was set at $30^{\circ} \mathrm{C}$.

For natural ventilation, all the operable windows were modeled as opened with initial outdoor wind speed at $0.5 \mathrm{~m} / \mathrm{s}$ and temperature of $24^{\circ} \mathrm{C}$. For mechanical ventilation, two Air Conditioning (AC) units were installed. The wind speed and temperature of the AC was set as $100 \mathrm{l} / \mathrm{s}$ and $24^{\circ} \mathrm{C}$, respectively (Fig.4.).

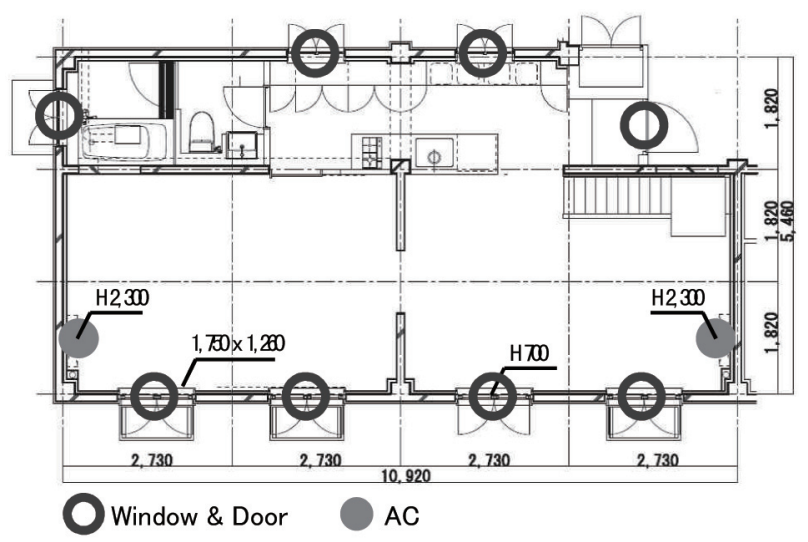

Fig.4. Location of the Window and AC

Both natural and mechanical ventilation were simulated with three different infill furniture layouts. To increase the direct impact of the storage furniture on the indoor condition, furniture such as tables, chairs, beds, etc. were not included in the CFD model, and this also reduced the computer power for simulation.

Wind speed and temperature were measured in six different areas. Table 2. shows the location of each measurement area.

The measuring area 6 indicates the overall area simulation results. For natural ventilation, the difference of average temperature between the three layouts shows $0.01^{\circ} \mathrm{C}$ and the wind speed difference was $0.02 \mathrm{~m} / \mathrm{s}$. For mechanical ventilation (AC), the average differences in layouts $\mathrm{A}, \mathrm{B}$, and $\mathrm{C}$ between temperature and speed are $0.12^{\circ} \mathrm{C}$ and $0.01 \mathrm{~m} / \mathrm{s}$, respectively. Considering the range of simulation errors, the overall area CFD simulation result shows no meaningful difference between layouts. However, comparing natural ventilation and mechanical ventilation (AC) shows an average difference of about $0.19 \mathrm{~m} / \mathrm{s}$ wind speed and about an average $1.8^{\circ} \mathrm{C}$ temperature difference.

In certain areas variations of furniture layout show meaningful differences. For mechanical ventilation, Layouts $\mathrm{A}$ and $\mathrm{C}$ show a temperature difference of $1.3^{\circ} \mathrm{C}$ in area 5 (Table 2.). Comparing the $\mathrm{ACH}$ difference between layouts, the difference for natural ventilation is $3.67 \mathrm{ACH}$ and that for mechanical ventilation (AC) is $0.24 \mathrm{ACH}$. This suggested that in certain instances moveable furniture (infill) creates a wind movement barrier to increase the temperature and wind speed difference between different spaces. The result of each CFD simulation and its relation to human behavior are described in more detail in section 4 .

\subsection{Daylight}

The centers of each measuring area within a height of $1.2 \mathrm{~m}$ from floor level are selected as points to measure the daylight factor. The typical glass transparency was set for the calculation. No internal shades are populated and no furniture was populated in the model except the storage furniture. Table 3 . shows the measuring points of the three cases.

The result shows that furniture layout 2 has a better daylight condition than the other two cases. In furniture layout 1 , point 1 has no direct daylight and the percentage of daylight factor for point 5 fell in excess of the general recommendation. Also, furniture layout 3 has similar results showing $0 \%$ for point 1 and $11.45 \%$ for point 5 . The average of each layout shows that layout type B has a higher daylight factor (5.8\%) than the other two layouts; however, the differences between the layouts are less than $1.69 \%$. Layout B shows more uniform distribution in terms of daylight factor. (Table 3.)

\section{Observing Resident's Living Behavior}

In order to understand how residents respond to the environment condition, the study chose a situation in which one person occupies the unit rather than a larger group of people. A larger number of occupants can cause a problem of privacy and make it difficult to observe the different behavior corresponding to the environment condition.

For that reason, the study investigates the days when a husband (a man in his fifties) occupies the unit for different scenarios. Based on the observation, the behavior map was developed for the three different furniture layout types. The behavior map is based on the participant's log in which each hour the participant's location was reported along with the length of time the participant stayed there and what type of action was conducted. The operation of controlling the mechanical ventilation (AC) system was not clearly reported in the behavior map, however observing the resident's living 
Table 2. Air Temperature and Wind Speed Factor for Different Layouts

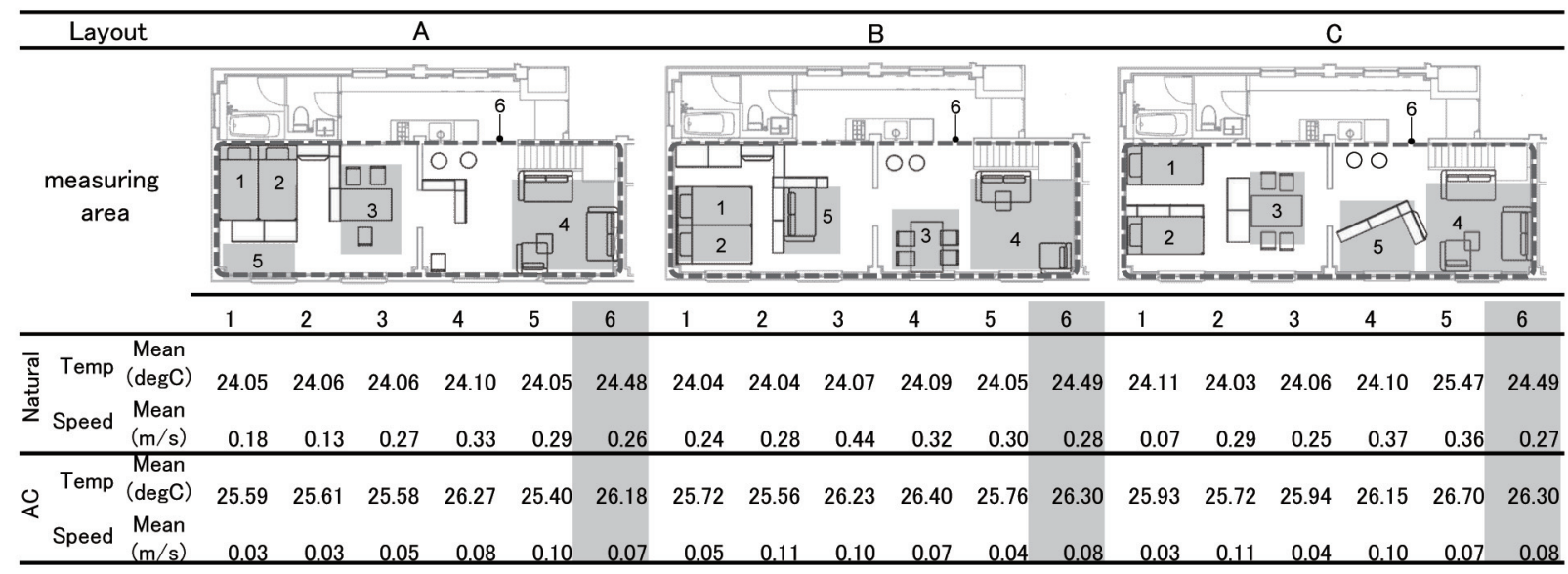

Table 3. Daylight Factor for Different Layouts

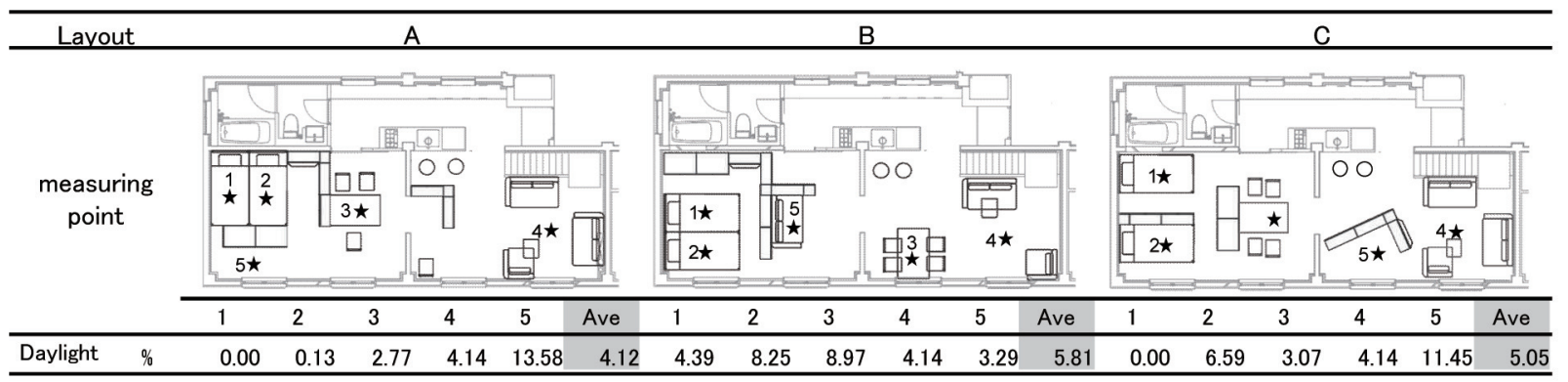

behavior shows that the resident usually operated the mechanical ventilation (AC) system to control the indoor environment condition. The behavior map was then compared with the simulation results to determine any connection between the participant's behavior and the environment condition (Table 4.).

The following section provides a comparison between the environmental condition and the resident's behavior for three different furniture layouts.

\subsection{Furniture layout type $A$}

From Apr. 26th to 27 th of 2006 , the resident (husband) stayed at the unit and the two visitors visited for about two and half hours. The resident prefers to sleep on the east side of the bed although the west side of the bed was available.

For working alone or meeting with visitors, the resident prefers to work at the dining table although in the layout designing stage the same action was expected to occur at the sofa area. Other events such as taking a rest occur at the sofa area, and having a meal occurs at the kitchen counter. Generally, the resident spends most of the time at the dining table (440min, 33.59\%) for working and the east side of the bed (515min, $39.31 \%$ ) for sleeping compared to other behaviors. The study found that the dining table area (area 3 and point 3) was $0.69^{\circ} \mathrm{C}$ cooler when $\mathrm{AC}$ was used and $1.37 \%$ lower in daylight factor than the sofa area (area and point 4), and other environment conditions show no significant difference. This suggested that the resident prefers to work in the cooler and darker area.

\subsection{Furniture layout type $B$}

The resident stayed in layout type B on Jul. 17th18th in 2006. During the stay, one visitor stopped by for about one hour. The resident slept on the south side of the bed although another bed was available on the north side. The resident worked alone at the dining table, and when the visitor was at the unit both worked on the east side sofa although the west side sofa was expected to be utilized in the layout design stage.

The resident spent the majority of the time working at the dining table $(325 \mathrm{~min}, 37.36 \%)$ but when working with the visitor, the resident worked on the east side sofa ( $80 \mathrm{~min}, 9.2 \%$ ). Simulation results show that the west sofa area (area 5) is $0.64^{\circ} \mathrm{C}$ cooler than the east sofa area (area 4) with mechanical ventilation (AC), but the other environment conditions show no difference. Between the dining table and the east sofa area (points 3, and 4), the daylight factor at the dining table (point 3 ) was $4.83 \%$ higher than that at the east side sofa area (point 4), but no significant difference was found for wind and temperature.

For the sleeping area, the south side bed area (point 2 ) is $3.86 \%$ higher than the north side (point 1 ), but the other environment conditions showed no difference.

The resident worked with the visitor at the east sofa area even though it was hotter than the west sofa area. This can be interpreted as the resident choosing the associated space for the workability rather than the thermal benefit. Comparison shows that for the working and sleeping areas, the resident stays at the area with better visibility. 
Table 4. Behavior and Environment Condition

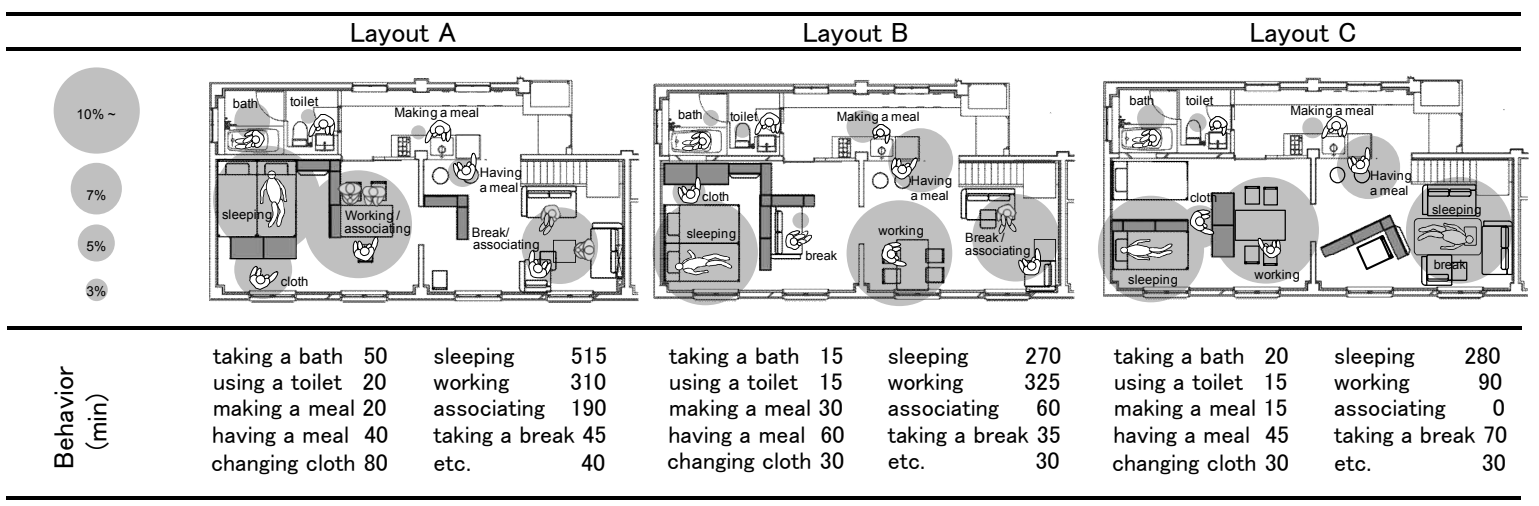
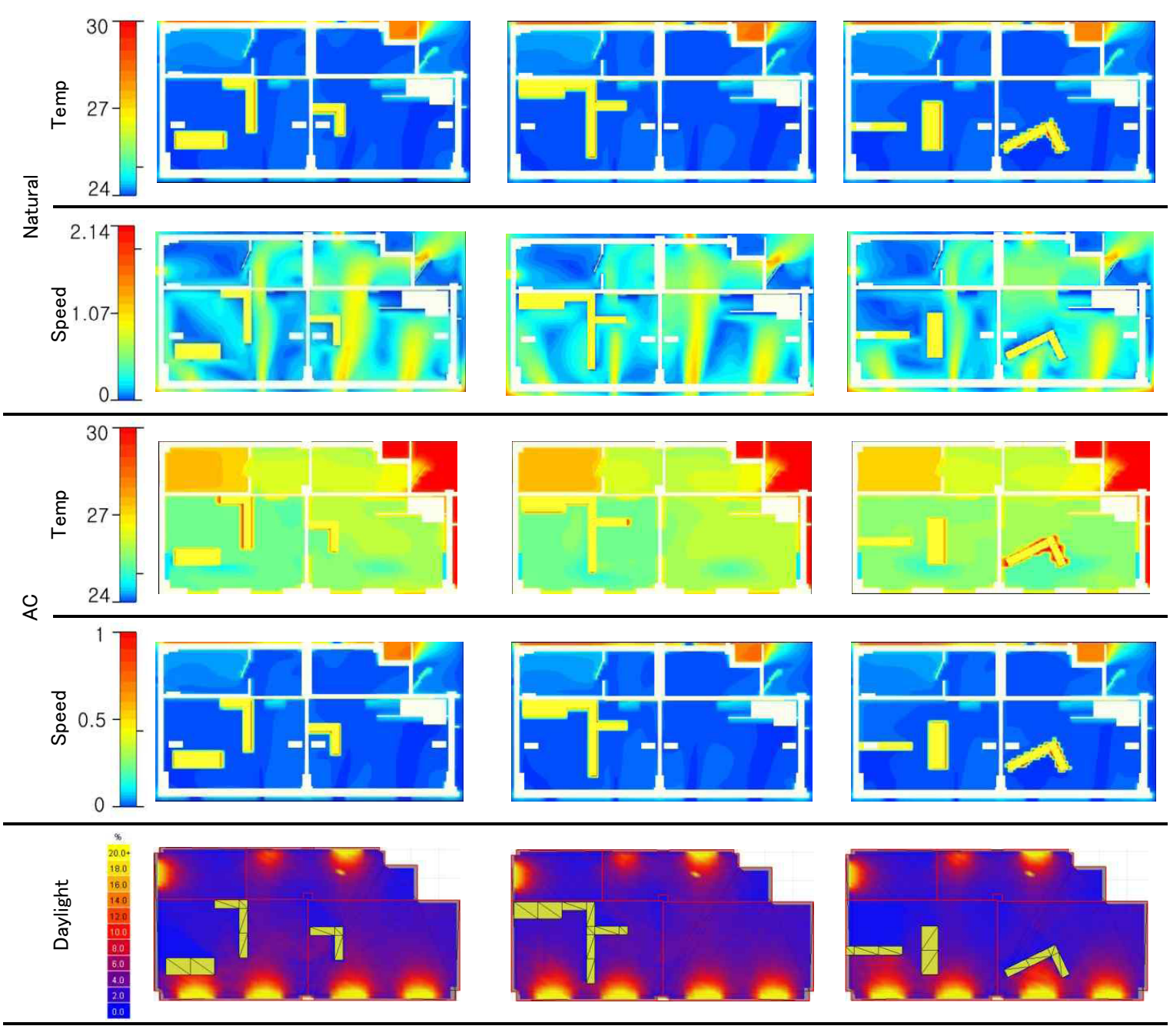

\subsection{Furniture layout type $C$}

On May 11th-12th in 2007, the resident (husband) and the visitor (in his sixties) stayed at the unit with the type C furniture layout. During the stay, the resident slept in the south bed, and the visitor slept in the futon on the east sofa area, although the north bed was available. The resident worked alone at the dining table, and took a break with the visitor at the east side sofa. This shows that the resident spends the majority of the time at both the dining table (90min, 15.13\%) and the sofa (70min, $11.76 \%$ ) areas. The south of the L-shape space with a sofa was expected to be used for a rest space in the layout design process; however, the sofa was moved to the east side and the space was used for storage.

The simulation result shows that the daylight factor in the east sofa area (point 4) was $1.07 \%$ higher than that in the dining table area (point 3), but no significant differences were found for wind and temperature.

Comparison between the east and south sofa areas (area $4 \&$ points 4 , and 5), shows that the east sofa area (area 4) is $1.37^{\circ} \mathrm{C}$ (natural) and $0.55^{\circ} \mathrm{C}(\mathrm{AC})$ cooler than the south sofa area (area 5). However, for the daylight, the daylight factor for the south sofa area (point 5) was $7.31 \%$ higher than that of the east sofa area (point 4). 
For the sleeping area, the daylight factor for the south side bed (point 2) is $6.95 \%$ higher than the north side bed (point 1), and the daylight factor for the east side sofa area (area $4 \&$ point 4 ) was $0.3 \mathrm{~m} / \mathrm{s}$ (natural) and $4.14 \%$ higher than the north side bed (area $1 \&$ point 1). The comparison indicates that the resident took a break in the cooler space and slept in the area with better visibility while the visitor slept at the area with better visibility and the cooler area.

\section{Discussion and Conclusion}

The study examined how environmental conditions could change according to different furniture layouts. Though temperature and wind speed of the overall space show no meaningful difference between the three layout types, each individual area for the three layouts shows different environmental conditions.

Overall, the $\mathrm{C}$ type layout, in which furniture divided the space into many small units, shows the main difference in temperature, wind speed and daylight factor. Layout B, in which furniture divides the space into two large spaces, shows a lower value for daylight factor compared to the two other layouts. It can be assumed that a furniture layout with basic and independent types creates various small spaces that create the various environment conditions.

The study also examined how residents respond to the environmental condition in a non-closed space. The resident prefers to occupy a space with better visibility for sleeping and a better thermal space for working in all three layouts; furthermore the study found that the resident moved to the sofa to the better temperature space in Layout type C.

This study assessed only a limited number of cases to understand residents' behavior, which means it is difficult to state that the findings can be generally applicable. However, the paper helps us to understand the importance of environmental factors and is able to suggest that the environmental condition generated by different moveable furniture (infill) is one of the major factors influencing resident behavior.

From the study, it is recommended that the residents' environmental preference be considered at the early infill design stage to develop various furniture layouts. This will create different environmental conditions and allow the resident to choose the preferred environmental condition.

\section{References}

1) Habraken N. J. (1998), The structure of the ordinary, MIT press: 132-135.

2) Hirohara Moriaki and other three (2002), Urban housing Science in an aging society, Minerva Publishing: 270-280.

3) Kazuhiko Nanba (2000), I want to live in a box house, Okokusha publishing: 60-61.

4) The NHK Broadcasting Culture Research Institute (2006), Survey on the ways of life of citizens in 2005: 4.

5) Peter Cook (1972), Archigram, London, Studio Vista: 44, 62.

6) Shinohara Satoko, other two, and a lifestyle workshop (2003), A changing family and a changing residence, Shokokusha publishing: 105.

7) Yi Yongkyu and other two (2006), An Examination of a change in the way of living in Flex Court Yoshida in which movable storage furniture is used, Urban Housing Sciences, 55:87-88.

8) Yi Yongkyu and Takada Mitsuo (2008), Modification on Movable Storage Furniture by Non-specialist, Architectural Research, Vol.10 No.2 : 1-10.

9) Yashiro Tomonari and other two (2004), Legal and Technological Feasibility Study on Refurbishment Method Using Flexible Infill System as Movable Property, Journal of architecture and planning, 577:135-142.

10) http://www.unhabitat.org/cdrom/docs/WUF2.pdf

11) http://www.kosis.kr/ 